\title{
PERSISTENCE OF INFECTIOUS HEMATOPOIETIC NECROSIS VIRUS (IHNV) IN STEELHEAD TROUT
}

\author{
Maureen K. Purcell ${ }^{1 *}$, Rachel L. Powers ${ }^{1,2}$, Natalia Ballesteros ${ }^{3 \S}$ \\ ${ }^{1}$ US Geological Survey, Western Fisheries Research Center, Seattle WA, 98115 USA \\ ${ }^{2}$ School of Aquatic and Fishery Sciences, University of Washington, Seattle, WA, 98105 USA \\ ${ }^{3}$ Centro de Investigaciones Biológicas, Departamento de Microbiología Molecular, 28040 Madrid Spain
}

\begin{abstract}
The existence of a carrier state for infectious hematopoietic necrosis virus (IHNV) has been debated for many years with some studies observing long-term persistence in salmonid hosts and other studies demonstrating rapid viral clearance below detectable levels. The question remains of interest because persistently infected fish may be a possible mechanism for maintaining the virus in natural salmon and trout populations. As part of a larger effort to model the landscape dynamics of IHNV in steelhead trout, we sought to assess the likelihood of IHNV persistence in this species using a field relevant virus strain. Steelhead trout experience a range of water temperatures, which influences the host response to virus. Colder water temperatures have been previously associated with persistence of aquatic rhabdoviruses in trout and other species. Steelhead trout were exposed to IHNV and fish were held at 6,10 or $15^{\circ} \mathrm{C}$. Mortality due to IHNV was significantly different at all three temperatures with the coldest temperature resulting in the highest mortality. Viral RNA persisted in a proportion of the fish at all three temperatures but the cold $\left(6^{\circ} \mathrm{C}\right)$ and intermediate $\left(10^{\circ} \mathrm{C}\right)$ groups had a higher proportion of the fish testing positive with nearly $50 \%$ of the fish still testing positive at 3 months post-infection. The warm $15^{\circ} \mathrm{C}$ group had the fewest fish testing positive for viral RNA and appeared to clear the virus more quickly relative to the intermediate and cold group. Viral clearance in the warm group is likely due to host factors rather than an impairment of viral replication as in vitro growth curves conducted in cell culture indicates that the virus replicates most efficiently at $15^{\circ} \mathrm{C}$. Previous studies in other fish hosts suggest that the brain can be a site of aquatic rhabdovirus persistence. In our study, we observed the highest frequency of viral RNA detections in the kidney and spleen at 6 and 9 months post-infection. This study used a highly sensitive RT-qPCR test to detect persistent viral RNA and importantly, this method does establish whether the virus is viable or infectious. Ongoing work seeks to characterize the host response to the virus at the 3 temperatures and to determine if infectious virus can be isolated from tissues harboring persistent viral RNA. In summary, IHNV persistence at the environmentally relevant temperature of $10^{\circ} \mathrm{C}$ may be more frequent than anticipated in steelhead trout but the question remain whether virus from these fish is transmissible and poses a risk.
\end{abstract}

\section{Keywords}

Temperature, transmission, natural populations, rhabdovirus, carrier

*Corresponding author: 206-526-2052, email: mpurcell@usgs.gov

${ }^{\S}$ Current address: University of Alabama, Birmingham 